\title{
FENOMENA MAL BAGI MASYARAKAT URBAN DI JAKARTA
}

\author{
Amarena Nediari \\ Interior Design Department, School of Design, BINUS Unoversity \\ Jln. K.H. Syahdan No.9, Palmerah, Jakarta Barat 11480 \\ anediari@binus.edu
}

\begin{abstract}
Mall building is a place where urban communities come together with their specific interest. People go to the mall with their independent needs without any emotional bonding between each other. As a public space, mall is trying to meet the needs of urban communities especially as an entertaining space for the visitors. Go to the mall has become a way of life in urban society, as a destination for the whole family. While on the other hand the existence of many mall building are the traits of sick city, because as a public space, city does not meet the social and environmental objectives anymore. Jakarta has more than 75 building mall, it has exceeded the limit of the population. Mall has become a phenomenon because it has met the lifestyle of urban society but on the other side mall has spent water absorption area. This disagreement about mall building requires a mall that friendly to the environment, so that the green open spaces and water absorption area can be provided or replaced as well. The next discussion is about mall that should build friendly to the environment and its importance to the urban community.
\end{abstract}

Keywords: mall, urban society, phenomenon

\begin{abstract}
ABSTRAK
Bangunan mal merupakan sarana untuk berkerumunnya masyarakat urban dengan kepentingan tertentu. Kepergian masyarakat ke mal adalah sebuah kepentingan independen tanpa adanya ikatan emosional antara satu sama lain. Sebagai ruang publik, mal berusaha untuk memenuhi kebutuhan masyarakat urban terutama sebagai ruang rekreasi bagi pengunjungnya. Berkunjung ke mal telah menjadi sebuah gaya hidup dari masyarakat urban, sebagai destinasi bagi seluruh anggota keluarga. Sementara di lain sisi, keberadaan banyak mal merupakan ciri-ciri kota sakit karena sebagai ruang publik kota tidak memenuhi tujuan sosial dan lingkungan. Jakarta sudah memiliki lebih dari 75 bangunan mal, hal ini telah melebihi batas ideal dari jumlah penduduknya. Sungguh mal telah menjadi sebuah fenomena karena telah memenuhi gaya hidup dari masyarakat urban, namun sekaligus telah menghabiskan ruang publik serta kawasan resapan air. Adanya kontroversi yang diberikan dari bangunan mal in membutuhkan sebuah mal yang ramah terhadap lingkungan sekitarnya sehingga ruang terbuka hijau serta kawasan resapan air tetap dapat tersedia ataupun tergantikan dengan baik. Pembahasan selanjutnya adalah mengenai bangunan mal yang ramah terhadap lingkungan dan kepentingannya terhadap masyarakat urban.
\end{abstract}

Kata kunci: mal, masyrakat urban, fenomena 


\section{PENDAHULUAN}

Kota merupakan pusat dari konsentrasi aktivitas ekonomi, sosial budaya, politik, pendidikan, dan administrasi pemerintahan telah menimbulkan pesona bagi masyarakat sekitarnya (Saidi, 2011). Dengandemikian, kota sebagai ruang publik mempunyai kebutuhan untuk dapat memenuhi kegiatan manusia di dalamnya. Kerumunan manusia yang terjadi di kota sering kali dirasa menakutkan, dan mengerikan bagi mereka yang baru pertama mengalaminya, dimana kerumunan sesaat ini terjadi dan dapat bubar sewaktu-waktu tanpa adanya ikatan secara emosional.

Walter Benjamin, seorang kritikus abad 20 yang menulis sejarah kota Paris sebagai ibu kota peradaban abad ke-19, mengatakan bahwa pada abad ke-19 pengalaman terhadap kota dianggap menghadang dan mengganggu sebagai akibat emosi yang dibangkitkan pada kerumunan yang terjadi di kota tempat mereka mengamati hal tersebut. Dalam bahasannya, penyair Prancis, Baudelaire, adalah yang pertama kali menggambarkan secara positif tentang pengalaman akan kerumunan, yaitu "manusia yang terjun ke dalam kerumunan seperti masuk ke dalam tandon energi listrik" (Supangkat, 2005). Ada sebuah kejutan yang akan dikenang sebagai sebuah pengalaman. Baik atau buruknya pengalaman tersebut tentu berpulang kembali pada latar belakang manusia yang akan membentuk persepsi mengenai pengalaman.

Bangunan mal merupakan sarana untuk berkerumunnya masyarakat urban dengan kepentingan tertentu. Kepergian mereka ke mal adalah sebuah kepentingan independen tanpa adanya ikatan emosional antara satu sama lain. Sebagai sebuah ruang publik, mal telah memenuhi kebutuhan masyarakat urban terutama sebagai ruang rekreasi bagi pengunjungnya. Hal ini telah menjadi sebuah gaya hidup dari masyarakat urban. Menghabiskan waktu di mal pada akhir minggu dianggap sebagai sebuah solusi bagi sebagian besar keluarga pada masyarakat urban. Hal yang tidak dapat dipungkiri, karena berbagai fasilitas dan sarana yang tersedia, mal menjadi one stop shopping yang memenuhi kebutuhan ayah yang ingin melengkapi koleksi hobinya, ibu yang ingin mencari tas, dan anak yang bermain games virtual di arena permainan. Bahkan sering dijumpai kereta dorong bayi (stroller) yang terisi penuh dengan kantong belanjaan sementara si adik sudah tertidur pulas dalam gendongan baby sitter.

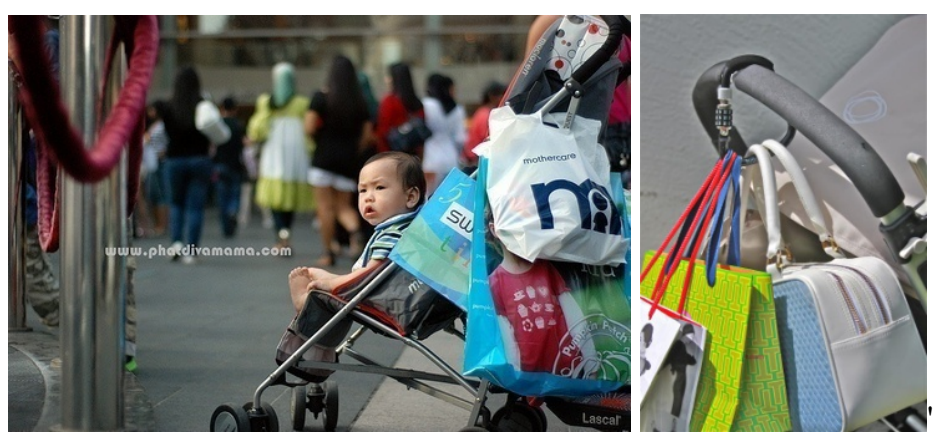

Gambar 1 Ilustrasi kereta dorong yang penuh dengan shopping bag merupakan hal yang umum dijumpai di mal

Keberadaan banyak mal merupakan ciri-ciri kota sakit. Karena sebagai ruang publik, kota tersebut tidak memenuhi tujuan sosial dan lingkungan (Atmawidjaja, 2011). Jumlah mal di Jakarta telah melebihi batas ideal dari jumlah penduduknya. Kota Jakarta telah memiliki lebih dari 75 bangunan mal (Yasir, 2012). " A shopping mall is an urban culture temple where we worship the trend god and bow before the fashion goddess" (Barraza, 2011). Mal sungguh telah menjadi sebuah 
fenomena karena telah memenuhi life style dari masyarakat urban namun sekaligus menghabiskan ruang publik hijau serta kawasan resapan air.

Berdasarkan kontroversi dari bangunan mal ini, dibutuhkan sebuah mal yang ramah terhadap lingkungan sekitar sehingga ruang terbuka hijau serta kawasan resapan air tetap dapat tersedia/tergantikan dengan baik. Oleh karena itu, peraturan akan pembangunan mal sebaiknya mendapat perhatian lebih saksama dari Pemerintah DKI Jakarta. Pembahasan selanjutnya adalah mengenai bangunan mal yang ramah terhadap lingkungan dan kepentingannya terhadap masyarakat urban.

\section{METODE PENELITIAN}

Penelitian dilakukan melalui pengumpulan data dari berbagai sumber literatur cetak maupun elektronik. Selain itu, penulis juga melakukan survei ke lokasi mal. Lebih lanjut, penulis melakukan wawancara dengan pihak manajemen mal sebagai narasumber.

\section{HASIL DAN PEMBAHASAN}

Mal merupakan kelompok kesatuan komersial yang dibangun di sebuah lokasi yang direncanakan, dikembangkan, dimulai, dan diatur menjadi sebuah unit operasi, berhubungan dengan lokasi, ukuran, tipe toko, dan area perbelanjaan dari unit tersebut. Unit ini juga menyediakan parkir yang dibuat berhubungan dengan tipe dan ukuran total toko-toko (Urban Land Institute, 1997).

Mal telah menjadi sebuah drama hidup, tempat orang benar-benar datang hanya untuk melihat dan mengatakan bahwa mereka di sana ataupun pernah ke sana (Moss, 2007). Ungkapan tersebut sangat sesuai dengan kondisi yang terjadi di Jakarta belakangan ini. Setiap mal berlomba-lomba untuk memberikan fasilitas dan program menarik sehingga pengunjung menyempatkan diri untuk datang menjadi bagian dari kerumunan. Program Jakarta Great Sale dalam rangka menyambut ulang tahun kota Jakarta dan program Midnight shopping yang diselenggarakan menjelang tahun baru ataupun hari raya merupakan salah satu event menarik bagi pengunjung mal di Jakarta. Kehirukpikukan dan keramaian yang terjadi dianggap sebagai sebuah keberhasilan program tersebut. Hal ini menggambarkan masyarakat urban yang menikmati menjadi bagian dari kerumunan.

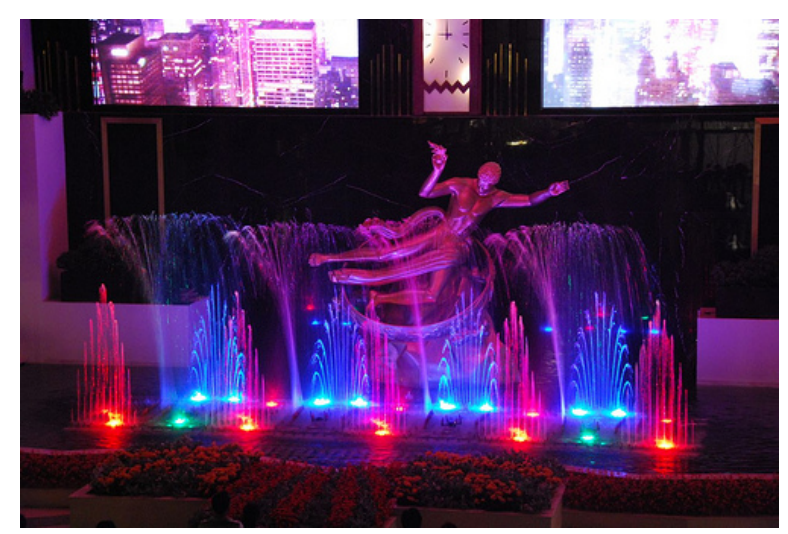

Gambar 2 Pertunjukan Water Fountain di Grand Indonesia: Atraksi Menarik bagi Pengunjung 
Pengalaman estetika merupakan sebuah ide bahwa estetika terus berkelanjutan dalam bentuk pengalaman sehari-hari, diungkapkan oleh John Dewey seorang filsuf Amerika (Supangkat, 2005). Masyarakat urban memiliki tingkat kemampuan ekonomi yang berbeda-beda. Mal memberikan beragam pengalaman bagi pengunjungnya, di antaranya adalah petualangan, hiburan dan imajinasi yang cerdas. Namun dalam pemahaman mal sebagai ruang publik yang memenuhi kebutuhan masyarakat urban, nyatanya setiap pengunjung dapat menyesuaikan diri dalam menikmati mal dengan caranya sendiri. Dari teori di atas mengenai pengalaman estetika, masyarakat urban akan tetap dapat menikmati mal, meskipun tanpa harus memaksakan diri untuk membeli, ataupun merasa malu untuk masuk ke dalam mal. Karena di dalam mal ini, masyarakat akan mendapatkan sebuah pengalaman menarik dan tak terlupakan dengan menikmati kemewahan, kecantikan dan keindahan ini tanpa sedikit pun dipungut biaya. Gaya hidup yang membuat masyarakat urban menjadi konsumtif karena merasa naik derajatnya dengan menjinjing tas belanjaan, ataupun merasa tampil cantik karena baru keluar dari salon penata rambut ternama. Akan tetapi, keharusan untuk masuk mal dan membeli tidak pernah tertulis pada peraturan mal.

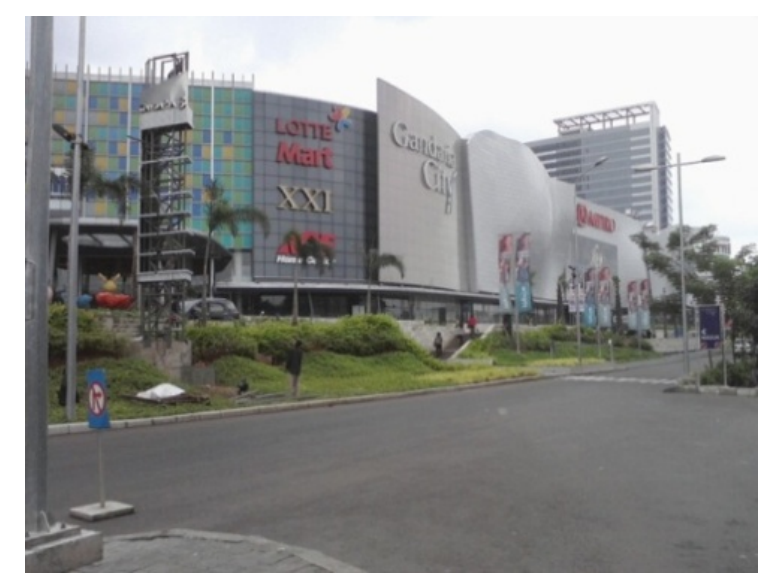

Gambar 3 Gandaria City: Mal Terbaru di Kawasan Jakarta Selatan

Hanya saja, sebagai ruang publik yang komersial, keberadaan toko-toko di dalam mal adalah untuk menjaring pelanggan dan menarik pembeli untuk membeli produknya. Keindahan mal bagi masyarakat urban tidak hanya semata terpenuhinya seluruh kebutuhan anggota keluarga dalam sebuah tujuan, tetapi juga masih ada faktor lainnya, seperti kenyamanan saat berjalan-jalan di dalam mal (terhindar dari teriknya sinar matahari maupun guyuran hujan), praktis dan efisien (mengurangi pergerakan di dalam kota), keamanan (memenuhi kebutuhan psikologis untuk rasa aman) serta kepastian (menghindari praktik penipuan produk yang lazim terjadi pada pasar tradisional). Selain itu, pengunjung mal juga mendapatkan pengalaman berbelanja yang menarik. Pada dasarnya, mal tidak memberikan belas kasihan dan tidak memberikan tujuan meskipun bagi pengunjungnya. Yang menentukan adalah manusia itu sendiri dengan kepergiannya menuju mal, dan yang akan dilakukan di mal dengan kemampuan yang dimiliki.

Secara struktur, menurut Rubinstein (1992), mal merupakan penggambaran dari kota yang terbentuk oleh elemen-elemen: Anchor (magnet) yaitu department store, Secondary Anchor (magnet sekunder) yang terdiri atas supermarket, superstore dan bioskop, kemudian street mall (berupa pedestrian yang menghubungkan antar-anchor, dan landscaping (pertamanan). Hal tersebut merupakan beberapa prinsip yang secara umum masih diterapkan dalam perencanaan dan pengembangan bangunan mal. 


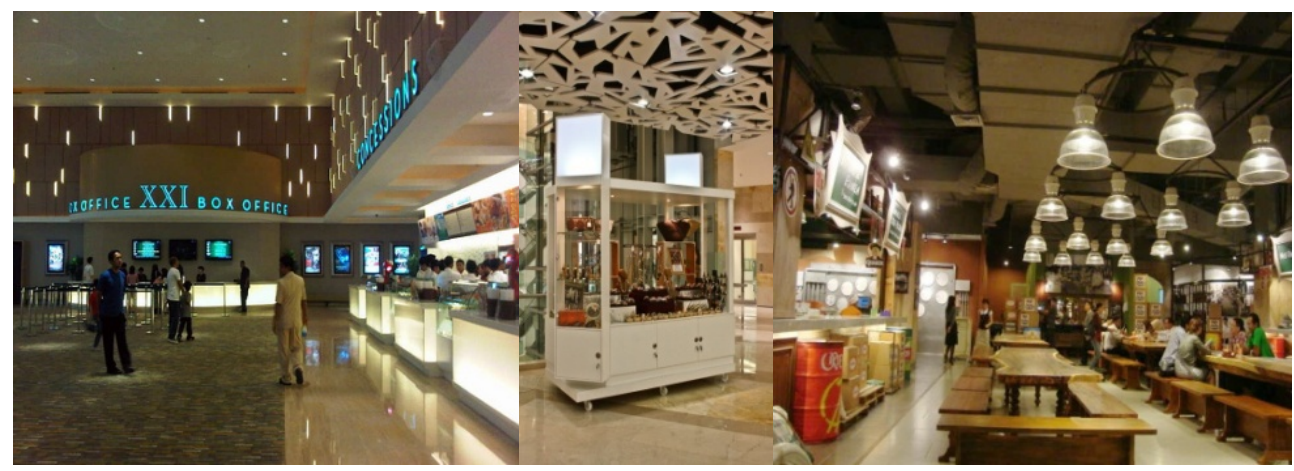

Gambar 4 Bioskop, Retail Store, dan Food Court sebagai Elemen Pembentuk Mal di Gandaria City

Dalam perkembangannya, struktur mal juga sempat mengalami evolusi. Sekitar pertengahan tahun 2005 Plaza EX tidak menerapkan anchor (department store) sebagai daya tarik utama, namun menempatkan Hard Rock Café sebagai pusat hiburan yang menjadi tujuan pengunjung mal. Akan tetapi, hingga saat ini belum terdapat data tertulis mengenai dampak yang ditimbulkan dari tidak adanya anchor sebagai daya tarik utama sebuh mal. Berdasarkan observasi lapangan yang dilakukan, bangunan mal tanpa department store terlihat kurang menarik jika dibandingkan dengan mal yang memiliki department store di dalamnya.

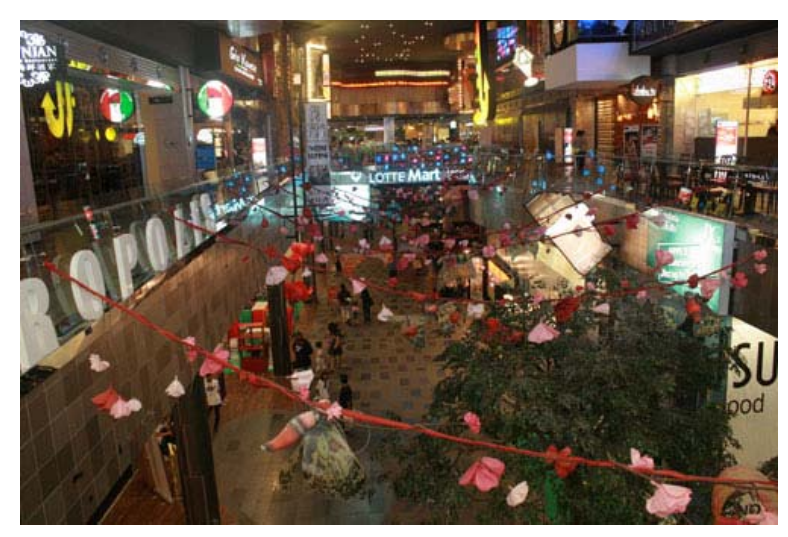

Gambar 5 Interior Mal yang Menampilkan Suasana Outdoor dan Pedestrian di Lantai Dasar Gandaria City

Mengenai keberadaan sebuah mal dan kepentingannya bagi masyarakat urban, Faisal Basri (calon Gubernur DKI Jakarta) mengungkapkan bahwa mal harus memenuhi tiga syarat minimal: harus ada ruang terbuka hijau, harus menyediakan ruang sosial bagi penduduk, dan harus memenuhi AMDAL (Analisis Mengenai Dampak dan Lingkungan). Hal ini disampaikan pada acara Sarasehan Independen untuk Jakarta di di Perpustakaan Nasional, Jl Salemba Raya, Jakarta Pusat (Analisis Mengenai Dampak dan Lingkungan) (Kuwado, 2012). Pendapat di atas sangat berkaitan dengan pembahasan fenomena mal di Jakarta sebagai kebutuhan masyarakat urban namun juga mempunyai dampak terhadap lingkungan.

Jika dilihat dari bentuknya, mal menurut Maithland (1987) mempunyai 3 (tiga) bentuk umum yaitu : Mal terbuka (Open Mall), Mal tertutup (Enclosed Mall) dan Mal Terpadu (Integrated Mall). 


\section{Mal Tertutup (Enclosed Mall)}

Mal tertutup adalah mal dengan pelingkup. Keuntungannya berupa kenyamanan climatic control. Kerugiannya biaya mahal dan kesan kurang luas. Mal jenis tertutup ini banyak berkembang di Jakarta pada era tahun 1990-an. Plaza Indonesia adalah salah satu contoh dari Enclosed Mall , terdiri dari empat lantai pertokoan kelas atas pertama di Jakarta. Sampai saat ini Plaza Indonesia menjadi pusat perbelanjaan eksklusif di Jakarta yang belum tergantikan oleh mal baru lainnya. Hal ini tentu saja didukung oleh sikap manajemen yang ingin selalu berkembang dan mempertahankan citranya yang eksklusif sehingga biaya perawatan yang mahal dari mal ini tentu masih dapat dipenuhi dengan biaya sewa yang tinggi.

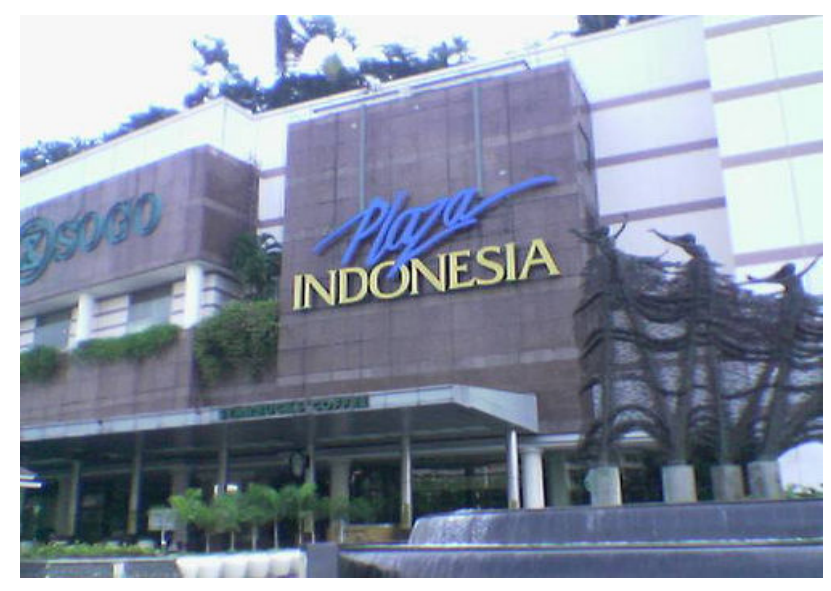

Gambar 6 Plaza Indonesia: Salah Satu Mal Tertutup di Jakarta

\section{Mal Terbuka (Open Mall)}

Mal terbuka adalah mal tanpa pelingkup. Keuntungannya adalah kesan luas dan perencanaan teknis yang mudah sehingga biaya lebih murah. Kerugiannya berupa kendala climatic control yang berpengaruh terhadap kenyamanan dan kurangnya kesan pewadahan. Tipe mal terbuka pada dasarnya sangat cocok jika diterapkan di negara-negara beriklim tropis. Untuk jenis mal ini, perencanaan arsitektur dan interiomya harus dapat memaksimalkan penghawaan dan pencahayaan alami pada bangunan.

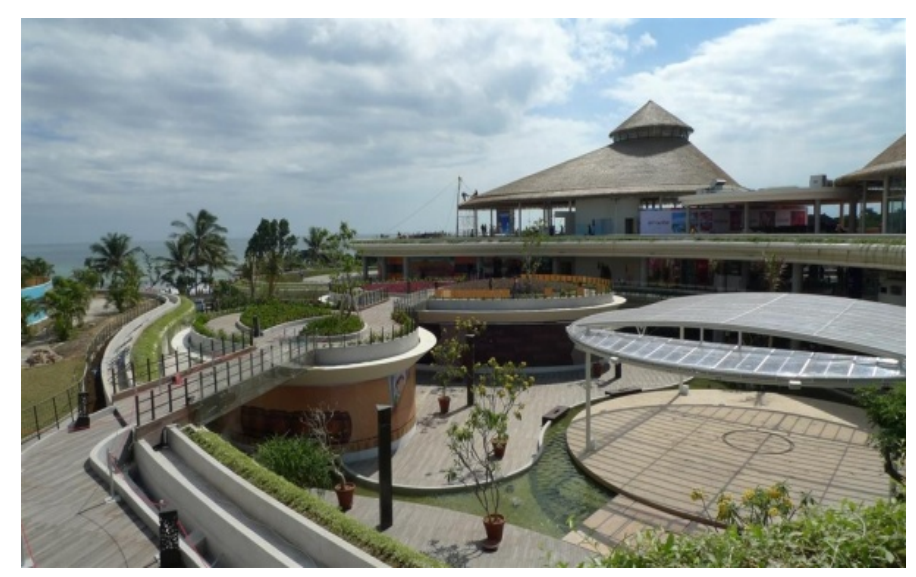

Gambar 7 Beach Walk di Kuta: Jenis Mal Terbuka (Open Mal) 


\section{Mal Terpadu (Integrated Mall)}

Mal terpadu adalah penggabungan antara mal terbuka dan tertutup. Biasanya, berupa mal tertutup yang mempunyai akhiran yang terbuka. Munculnya bentuk ini merupakan antisipasi terhadap keborosan energi untuk climatic control serta mahalnya pembuatan dan perawatan mal tertutup.
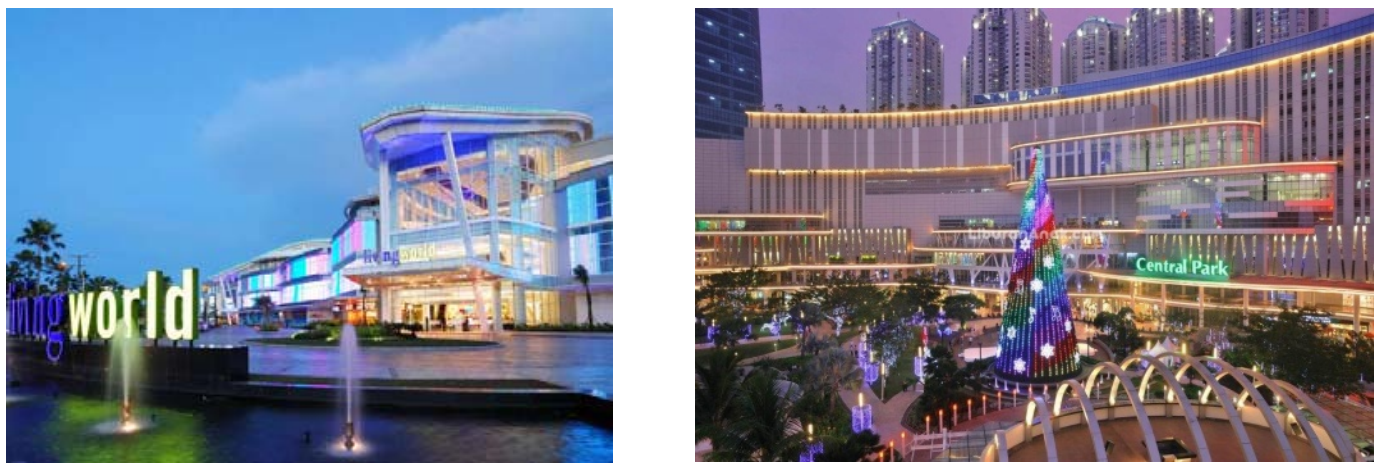

Gambar 8 Living World - Alam Sutera dan Mal Central Park - Jakarta Barat: contoh dari integrated mal

Jenis bangunan terbuka dan desain yang ramah lingkungan saat ini tengah menjadi tren di dunia. Di Indonesia sendiri konsep bangunan yang ramah lingkungan ini telah diatur dalam Peraturan Menteri Negara Lingkungan Hidup no. 8 tahun 2010 yaitu tentang Kriteria dan Sertifikasi Bangunan Ramah Lingkungan. Di sini diungkapkan bahwa bangunan ramah lingkungan (green building) adalah suatu bangunan yang menerapkan prinsip lingkungan dalam perencanaan, pembangunan, pengoperasian dan pengelolaannya, dan aspek penting penanganan dampak perubahan iklim. Selain itu, sebuah organisasi nonprofit Green Building Council Indonesia (GBCI) sebagai bagian dari organisai World Green Building Council (WGBC) dapat memberikan sertifikasi bangunan hijau di Indonesia berdasarkan perangkat nilai khas Indonesia yang bernama Greenship. Sertifikasi Bangunan Hijau ini diharapkan dapat membuat para pengembang mal sadar pentingnya bangunan dengan desain yang ramah lingkungan. Karena Greenship ini diakui dunia, tentu akan berpengaruh sebagai pencapaian baik dari pengembang.

\section{SIMPULAN}

Fenomena mal terhadap masyarakat urban di Jakarta dan dampaknya terhadap lingkungan adalah bahwa mal memberikan pengalaman estetika bagi masyarakat urban. Estetika sebagai persepsi penginderaan menjadikan kunjungan ke mal sebagai pengalaman yang berharga. Walaupun mal telah menjadi destinasi dari gaya hidup masyarakat urban, budaya konsumtif bukanlah aturan baku yang selalu diikuti. Tingkat pendidikan dan keterbatasan ekonomi juga turut berperan dalam gaya hidup masyarakat urban.

Kebutuhan masyarakat urban akan mal tentu dipengaruhi oleh tren yang selalu bergeser. Bangunan yang terbuka dan ramah lingkungan saat ini menjadi tren di dunia, memberikan dampak yang positif bagai perkembangan dunia interior-arsitektur. Hal ini memberikan kesadaran bagi masyarakat urban tentang pentingnya sebuah ruangan hijau terbuka dan daerah resapan air. Dampak dari bangunan mal terhadap lingkungan saat ini dapat diatasi dengan memberikan kebijakan mengenai aturan pembangunan mal di kota Jakarta melalui Peraturan Menteri Negara Lingkungan Hidup no. 8 tahun 2010 guna mendapatkan sertifikasi bangunan hijau dari Green Building Council Indonesia 
(GCBI). Dengan demikian, perencanaan bentuk arsitektur-interior bangunan mal bagi masyarakat urban dapat memberikan ruang hijau serta kawasan resapan air. Lebih lanjut, masyarakat urban di Jakarta mempunyai mal yang ramah terhadap lingkungan.

\section{DAFTAR PUSTAKA}

Atmawidjaja, E. S. (2011). Masikah Kota Kota di Indonesia Butuh Mal. Bulletin penataan ruang .

Barraza, E. (2011, May 9). Shopping Malls: Urban Culture Temples. Retrieved February 17, 2012, from Hispanic Institute of Social issue : www.barriozona.com

Kurniady, T. (2011, may 31). Tinjauan Umum . Retrieved February 17, 2012, from Pengertian mal: www.scribd.com

Kuwado, F. J. (2012, January 25). Tidak Mudah Mengumpulkan Setengah Juta KTP. Retrieved February 16, 2012 from Megapolitan: www.kompas.com.

Moss, M. H. (2007). Shopping as an Entertaining Experience. United Kingdom: Lexington Books.

Saidi. (2011). Urban art and Culture. Catatan Perkuliahan Magister Desain. Jakarta: Universitas Trisakti.

Supangkat, J. T. O. (2005). Urban/Culture. Jakarta : Kepustakaan Populer Gramedia .

Underhill, P. (2004). Call of the Mall. New York: Simon \& Schuster Paperback.

Yasir, M. (2012, April 11). Daftar Mal di Jakarta . Retrieved 08 08, 2012, from 101 kata Muhammad Yasir : http://muhyasir.wordpress.com/2012 